\title{
IDENTIFYING THE EFFECTIVE TEACHER: THE CONCEPTIONS OF PRE-SERVICE ASSISTANT NURSES
}

\author{
Katerina Kasimatis ${ }^{1}$, Vasiliki Kontogianni ${ }^{2}$, Andreas Moutsios-Rentzos ${ }^{3}$, \\ \& Varvara Rozou ${ }^{4}$ \\ ${ }^{l}$ Department of Education, School of Pedagogical and Technological Education ASPETE (Greece) \\ ${ }^{2}$ Vasiliki Kontogianni, Psychiatric Hospital of Attica (Greece) \\ ${ }^{3}$ Department of Pedagogy and Primary Education, National and Kapodistrian \\ University of Athens (Greece) \\ ${ }^{4}$ Department of Philosophy, National and Kapodistrian University of Athens (Greece)
}

\begin{abstract}
In this paper, we focus on the conceptions of effective teaching that pre-service assistant nurses hold about effective and ineffective teaching during their training in Public Vocational Training Institutes (DIEK) in Greece. We focused on three aspects of teaching effectiveness: 1) The model of Patrick and Smart (1998), who identified three groups of effective teacher characteristics includes; respect for students, ability to challenge students, organisation and presentation skills; 2) Considering the hands-on teaching experiences of pre-service assistant nurses, we explored their conceptions about teaching effectiveness in problem-based learning educational settings, based on Mayo, Donnelly, Nash and Schwartz (1993), who investigated, amongst others enthusiasm, active interaction and providing feedback. 3) The communicational aspect of teaching effectiveness, drawing upon the work of McCroskey and Richmond (1990) about socio-communicative styles, who identified two dimensions of interpersonal communication; namely assertiveness and responsiveness. All three aspects were explicitly investigated for both effective and ineffective teaching. A three-section (in line with the three-faceted conceptualisation of teaching effectiveness), 56 Likert-type items, questionnaire was completed by 125 students. Our analyses allowed us to identify which aspects of teaching characterise the effective teacher and which are present both in the effective and the ineffective teacher.
\end{abstract}

Keywords: Effective teaching, nurse education, assistant nurses, vocational education.

\section{Introduction}

Effective teaching in diverse educational settings has gathered the interest of numerous research projects, adopting various theoretical and methodological lenses (Creemers, \& Kyriakides, 2008; Muijs, \& Reynolds, 2017). Moreover, the current economic situation has gathered the research focus on vocational education and training (Mouzakitis, 2012) that seems to be amongst the priorities of various countries (see, for example, OECD, 2015), since most of the industrialized countries need to equip their labor force with the new abilities that the labor market demands. In the European context, vocational education emerged in 1990 due to socio-economic factors and transformations. Vocational Education and Training supports individuals to obtain specialized scientific and technical knowledge, improves transition to employment and enhances employability. For example, Biavaschi et al. (2012) revealed an increase of the demand for the connection of youth into labor markets.

In modern societies, nursing education has the pioneering role of producing motivated, competent, qualified and caring professional nurses. Nursing educators hold the key role of the transformation of nursing students to professional practitioners. In Greece, poor staff-patient ratios and the shortage of qualified nurses have been also evident in Greek hospitals over the last few years (Kentikelenis, \& Papanicolas, 2011), underlying the increased need for qualified nurses to meet challenges and increased responsibilities. However, assistant nurses' education and training has not been as extensively researched. In this study, we focus on assistant nurses who are trained in Vocational Training Institutes (IEK) and in particular Public Vocational Education and Training (DIEK). Post-secondary vocational education in Greece aims at the increase of an individual's productivity and results to recognized qualifications or equips people with exploitable knowledge and necessary skills for 
the execution of a set of work (occupational specialization). Vocational Education and Training offers preliminary training alternating between theoretical lessons and classes in workshops (hands on). Over the last decade the Greek government has upgraded vocational training aiming to empower individuals, provide them with the necessary skills for active participation in society and promote employment. Since 1990, IEKs and DIEKs provide several specializations in nursing (Nursing Traumatology, Operating Room nursing, Nursing People with Mental Conditions, Intensive Care Unit nursing etc).

A large body of research has focused on the subject of comparing effective and ineffective teaching behaviors. Most of them reveal that effective nursing teaching practices are crucial to the development and production of competent practitioners. Acknowledging the growing interest in vocational education and, in particular, the importance of providing effective training to the particular population, this study attempts to add to this body of research by investigating the conceptions of pre-service assistant nurses (who study in DIEKs) about teaching effectiveness and ineffectiveness in Greece.

\section{Nurse education and effective teaching}

Nurse education requires appropriate teaching that supports future nurses to obtain a concrete knowledge base that can provide them with the necessary skills and equip them to confidently manage the complex components of clinical practice. Rush, Acton, Tolley, Marks-Maran, and Burke (2010) stress that the health-care system is constantly changing demanding more from nurses and focuses on the need for nurses that can think quickly and effectively, make accurate assessments, solve problems and take decisions. Moreover, over the last decades, a paradigm shift has occurred in nursing education; from a teacher to learner centered approach and from the theory to practice. There is an emerging need for nursing education to be effectively connected to the nursing practice, so that nursing students can be more prepared for their future role and responsibilities in the complex health care environment. Nurse educators need to avoid traditional passive lecture styles and to adopt the use of tools and techniques which facilitate reducing the gap between theory and practice (Wells et al., 2002), including the use of technology as a teaching tool, Project-Based Learning Strategies, simulations, Problem Based Learning (PBL) and role playing (Durham, \& Alden, 2008). Furthermore, today's complex societies demand for nurses to possess strong communication skills. The teachers' communication behavior impacts on student's outcomes and their communicative style.

Considering the two-faceted education of pre-service assistant nurses (theoretical and hands-on), we argue that teacher effectiveness should address both aspects. Regarding hands-on teaching effectiveness, medical schools seem to employ problem-based learning (PBL). Mayo, Donnelly, Nash and Schwartz (1993) focused on the identification of the effective tutors' characteristics in a PBL educational setting. Although PBL first appeared in the 1950s in medical schools in the United States, it is a contemporary pedagogical strategy for posing real world situations, resources and instruction to students, as they develop problem-solving skills (Mayo et al, 1993). The findings of their study indicated that the students viewed the average PBL tutor as competent in all the evaluated skills. The tutors that were most highly rated were the ones that showed enthusiasm, actively interact with the students and exhibited a high degree of comfort outside their areas of expertise. Moreover, the effective tutor helps students to identify issues of importance, errors and deficiencies and provides feedback to students. Feedback is a core feature of an effective tutor and should come not only from tutor but also from the students.

At the same time, an important measure of teacher effectiveness except from teachers' sociocommunicative orientation are teachers' personal traits and qualities. Research has revealed that a high level of teacher competency results to increased student engagement and consequently to better leaning outcomes (Curran, \& Rosen, 2006; Paswan, \& Young, 2002). In the current study we adopted McCroskey and Richmond's (1990) views to examine relations among perceived sociocommunicative styles and teacher effectiveness. McCroskey and Richmond (1990) focused on the empirical relations between personality's unique characteristics and traits and communicative behavior. An integral part of their research is the assumption that the personality of an individual has significant impacts on the communication behavior and that it has a biological base (see also, Beatty, McCroskey, \& Valencic, 2001). More specifically, they suggested that the two basic components/dimensions of interpersonal communication are assertiveness and responsiveness. Responsiveness characterizes an individual who "considers other's feelings, listens to what others have to say, and recognizes the needs of others" (Richmond \& Martin, 1998, p. 136-137), while assertiveness refers to the individuals that "are able to initiate, maintain, and terminate conversations, according to their interpersonal goals" (p. 136). As a result, McCroskey \& Richmond (1990) suggested that teachers who present responsiveness to their students, enhance cognitive and affective learning than the ones not as responsive. 
In the current study, we adopted Patrick and Smart's (1998) teacher characteristics that have been also evident in other research studies on teacher effectiveness. The teacher competencies evaluated in this study, are respect for students, the ability to challenge students, and having presentation and organizational skills. The research study of Patrick and Smart (1998) was conducted in two distinct phases. In phase one, undergraduate students identified specific qualities of effective teachers. In phase two they made use of items from existing tools that measure effective teaching and combined them with items occurred from students' responses in phase one, in order to form a meta-inventory. This meta-inventory was administered to undergraduate students. The analysis revealed that teacher effectiveness has a multi-dimensional nature, consisting of thirty-six effective teacher attributes, qualities or activities, that can be organised in three groups: respect for students, ability to challenge students, organisation and presentation skills.

All three aspects (general and hands-on teaching characteristics, as well as socio-communicative styles) were explicitly investigated for both effective and ineffective teaching, thus allowing for the effective and the ineffective teaching aspects to not a priori diverge.

\section{Methods and procedures}

A three-section, 56 Likert-type items, questionnaire was completed by 125 students $(\mathrm{N}=125$; from 6 DIEKs) in November 2016. Each section included the questionnaires developed by the aforementioned theorists - 24 items, Patrick and Smart (1998), 12 items Mayo et al (1993), 20 items McCroskey and Richmond (1990). It should be stressed, that all items for all scales were transformed to dyads, explicitly requiring the participants to provide answers for both the effective and the ineffective teacher.

We adopted the SocioCommunicative Orientation Scale (SCO) of McCroskey and Richmond (1990). In particular, 20 7-point Likert type items were employed: 10 items to measure responsiveness and 10 to measure assertiveness. According to Mayo et al. (1993) the students evaluate their tutors on 12 characteristics hypothesised to be essential for effective teaching and, respectively, 12 7-scale Likert type items operationalise this perspective. Considering Patrick and Smart (1998), three scales (each consisting of 8 7-point Likert type items) measure the three dimensions of teacher effectiveness (respect, organisation, challenge).

The factorial analyses (Principal Axis Factoring), followed by reliability analyses (Cronbach's alpha), supported the validity and reliability of the employed measures. The convergence between the conceptions of the pre-service DIEK students about the ineffective and the effective teacher was calculated as the difference between the respective answers for each scale. The Wilcoxon Signed Rank Test was used to identify statistically significant difference (chosen at $P<0.05$ ) from the conceptual neutral or from complete agreement. All the analyses were conducted with SPSS 25.

\section{Results}

The results of the conducted analyses are summarised in Table 1. Note that the scales range from ' 1 ' to ' 7 ' (referring to respectively 'completely disagree' and 'completely agree'), with the conceptual median being ' 4 '. In addition, the agreement on effective and non-effective responses was calculated as the difference between the replies given. In this case, the agreement values ranged from ' -6 ' to ' +6 ', with ' 0 ' denoting complete agreement between them.

The effective teacher was found to be statistically significantly more responsive than the ineffective teacher, but not statistically significantly different from the ineffective teacher with respect to assertiveness. Moreover, for responsiveness, the effective teacher was statistically significantly higher than the conceptual neutral, whilst the ineffective was statistically significantly lower than the conceptual neutral. On the contrary, no statistically significantly differences from the conceptually neutral with respect to assertiveness were identified or both the effective and the ineffective teacher

Furthermore, the effective teacher was found to be statistically significantly higher with respect to respect, organisation and challenge than the ineffective teacher. Importantly, in all three scales, the effective teacher was statistically significantly higher than the conceptual neutral, whilst the ineffective was statistically significantly lower than the conceptual neutral.

Considering the 'hands-on' effective and ineffective teacher, the analysis was done at the level of queries in line with the original study. For all twelve items, the effective teacher was statistically significantly higher than the conceptual neutral, whilst the ineffective was statistically significantly lower than the conceptual neutral. At the same time, the effective teacher was found to be statistically significantly more on the positive for all the measured characteristics. 
Table 1. Conceptions of the effective and ineffective teacher of pre-service assistant nurses in DIEKs.

\begin{tabular}{|c|c|c|c|c|c|c|c|}
\hline & & \multicolumn{6}{|c|}{ Convergence } \\
\hline & & $M$ & $S D$ & $P$ & $M$ & $S D$ & $P$ \\
\hline \multirow[t]{2}{*}{ Responsiveness } & Effective & 5.9 & 0.9 & $<0.001$ & 3.3 & 2 & $<0.001$ \\
\hline & Ineffective & 2.6 & 1.5 & $<0.001$ & & & \\
\hline \multirow[t]{2}{*}{ Assertiveness } & Effective & 4.2 & 1.1 & 0.162 & 0.3 & 1.8 & 0.118 \\
\hline & Ineffective & 3.8 & 1.3 & 0.185 & & & \\
\hline \multirow[t]{2}{*}{ Respect } & Effective & 5.9 & 1 & $<0.001$ & 3.6 & 1.9 & $<0.001$ \\
\hline & Ineffective & 2.4 & 1.3 & $<0.001$ & & & \\
\hline \multirow[t]{2}{*}{ Organisation } & Effective & 6.3 & 0.9 & $<0.001$ & 4.1 & 1.8 & $<0.001$ \\
\hline & Ineffective & 2.2 & 1.3 & $<0.001$ & & & \\
\hline \multirow[t]{2}{*}{ Challenge } & Effective & 6 & 1 & $<0.001$ & 3.7 & 1.8 & $<0.001$ \\
\hline & Ineffective & 2.3 & 1.3 & $<0.001$ & & & \\
\hline \multirow[t]{2}{*}{$\begin{array}{l}\text { Asks Thought-Provoking } \\
\text { Questions }\end{array}$} & Effective & 6.2 & 1.3 & $<0.001$ & 4 & 2.3 & $<0.001$ \\
\hline & Ineffective & 2.2 & 1.6 & $<0.001$ & & & \\
\hline \multirow[t]{2}{*}{$\begin{array}{l}\text { Helps Group Be Aware of How } \\
\text { It Is Working }\end{array}$} & Effective & 6.2 & 1.2 & $<0.001$ & 4.1 & 2.2 & $<0.001$ \\
\hline & Ineffective & 2.1 & 1.5 & $<0.001$ & & & \\
\hline \multirow[t]{2}{*}{$\begin{array}{l}\text { Encourages Effective Feedback } \\
\text { Within Group }\end{array}$} & Effective & 6 & 1.2 & $<0.001$ & 3.7 & 2.1 & $<0.001$ \\
\hline & Ineffective & 2.3 & 1.4 & $<0.001$ & & & \\
\hline \multirow[t]{2}{*}{ Shows Enthusiasm for Group } & Effective & 5.6 & 1.4 & $<0.001$ & 3.1 & 2.2 & $<0.001$ \\
\hline & Ineffective & 2.4 & 1.5 & $<0.001$ & & & \\
\hline \multirow[t]{2}{*}{$\begin{array}{l}\text { Actively Contributes, Shares } \\
\text { Info and Experiences }\end{array}$} & Effective & 6.3 & 1.2 & $<0.001$ & 4 & 2.3 & $<0.001$ \\
\hline & Ineffective & 2.3 & 1.6 & $<0.001$ & & & \\
\hline \multirow[t]{2}{*}{$\begin{array}{l}\text { Ensures That Group Stays "On } \\
\text { Track" }\end{array}$} & Effective & 6.2 & 1.2 & $<0.001$ & 4 & 2.2 & $<0.001$ \\
\hline & Ineffective & 2.2 & 1.5 & $<0.001$ & & & \\
\hline \multirow[t]{2}{*}{$\begin{array}{l}\text { Helps Group Identify Errors or } \\
\text { Deficiencies }\end{array}$} & Effective & 6.4 & 1 & $<0.001$ & 4.3 & 1.9 & $<0.001$ \\
\hline & Ineffective & 2.1 & 1.4 & $<0.001$ & & & \\
\hline \multirow[t]{2}{*}{$\begin{array}{l}\text { Helps Group Set Learning } \\
\text { Issues }\end{array}$} & Effective & 6.2 & 1.2 & $<0.001$ & 3.9 & 2.2 & $<0.001$ \\
\hline & Ineffective & 2.2 & 1.4 & $<0.001$ & & & \\
\hline \multirow[t]{2}{*}{$\begin{array}{l}\text { Promotes Use of Outside } \\
\text { Resources }\end{array}$} & Effective & 6.1 & 1.3 & $<0.001$ & 3.7 & 2.4 & $<0.001$ \\
\hline & Ineffective & 2.3 & 1.5 & $<0.001$ & & & \\
\hline \multirow[t]{2}{*}{ Promotes Psychosocial Issues } & Effective & 5.9 & 1.5 & $<0.001$ & 3.6 & 2.3 & $<0.001$ \\
\hline & Ineffective & 2.3 & 1.5 & $<0.001$ & & & \\
\hline \multirow[t]{2}{*}{$\begin{array}{l}\text { Exhibits Comfort Outside Area } \\
\text { of Expertise }\end{array}$} & Effective & 5.5 & 1.6 & $<0.001$ & 3 & 2.6 & $<0.001$ \\
\hline & Ineffective & 2.5 & 1.7 & $<0.001$ & & & \\
\hline \multirow[t]{2}{*}{$\begin{array}{l}\text { Helps Integrate Learning } \\
\text { Issues }\end{array}$} & Effective & 5.9 & 1.4 & $<0.001$ & 3.6 & 2.5 & $<0.001$ \\
\hline & Ineffective & 2.3 & 1.6 & $<0.001$ & & & \\
\hline
\end{tabular}




\section{Discussion, concluding remarks and recommendations.}

The quantitative analyses revealed that though the students' conceptions about the effective teacher were in line with the literature (with the effective teacher statistically significantly including the expected characteristics for all the main measured aspects and dimensions), their conceptions about the ineffective teacher were not always found to statistically significantly differ from the effective (notably about assertiveness). Thus, our analyses allowed us to identify which aspects of teaching characterise the effective teacher (and not the ineffective teacher) and which are present both in the effective and the ineffective teacher. The findings of the study suggest that the pre-service assistant nurses have clear-cut conceptions about teaching effectiveness in most of the measured aspects. The fact that assertiveness did not arise as a differentiating factor between effective and ineffective teacher renders to be further investigated with larger samples, but, importantly, through qualitative techniques to delineate the links of these conceptions with the teaching practices and/or the particular characteristics of the assistant nursing profession.

\section{References}

Biavaschi, C., Eichhorst, W., Giulietti, C., Kendzia, M. J., Murayev, A., Pieters, J., Rodriguez-Planas, N., Schmidl, R. \& Zimmermann, K. F. (2012). Youth unemployment and vocational training. IZA Discussion Paper. DP No. 6890.

Creemers, B. P. M., \& Kyriakides, L. (2008). The dynamics of educational effectiveness: A contribution to policy, practice and theory in contemporary schools. London and New York: Routledge.

Curran, J. M., \& Rosen, D. E. (2006). Student attitudes toward college courses: An examination of influences and intentions. Journal of Marketing Education, 28(2), 135-148.

Durham, C. F., \& Alden, K. R. (2008). Enhancing Patient Safety in Nursing Education Through Patient Simulation. In R. G. Hughes (Ed.), Patient Safety and Quality: An Evidence-Based Handbook for Nurses (Vol. 3, pp. 220-260). Rockville, MD: Agency for Healthcare Research and Quality.

Kentikelenis, A., \& Papanicolas, I. (2011) Economic crisis, austerity and the Greek public health system. European Journal of Public Health, 22(1), 4-5.

Mayo, P., Donnelly, M. B., Nash, P. P., \& Schwartz, R. W. (1993). Student perceptions of tutor effectiveness in a problem-based surgery clerkship. Teaching and Learning in Medicine: An International Journal, 5(4), 227-233.

McCroskey, J. C., \& Richmond, V. P. (1990). Willingness to communicate: Differing cultural perspectives. Southern Journal of Communication, 56(1), 72-77.

Mouzakitis, G. S. (2010). The role of vocational education and training curricula in economic development. Procedia-Social and Behavioral Sciences, 2(2), 3914-3920

Muijs, D., \& Reynolds, D. (2017). Effective teaching: Evidence and practice. London: Sage.

OECD, (2015). OECD Reviews of Vocational Education and Training. Available at http://www.oecd.org/education/skills-beyondschool/OECD_VET_Key_Messages_and_Country_Summaries_2015.pdf

Paswan, K., \& Young, J. A. (2002). Student evaluation of instructor: A nomological investigation using structural equation modeling. Journal of Marketing Education, 24 (3), 193-202.

Patiniotis, N. \& Stavroulakis, D. (1997. The development of vocational education policy in Greece: a critical approach. Journal of European Industrial Training, 21 (6), 192-202.

Patrick, J., \& Smart, R. M. (1998). An empirical evaluation of teacher effectiveness: The emergence of three critical factors. Assessment \& Evaluation in Higher Education, 23(2), 165-178.

Pozo-Munoz, C., Rebolloso-Pacheco, E., \& Fernandez-Ramirez, B. (2000). The 'Ideal Teacher'. Implications for student evaluation of teacher effectiveness. Assessment \& Evaluation in Higher Education, 25(3), 253-263.

Richmond, V. P., \& Martin, M. M. (1998). Sociocommunicative style and sociocommunicative orientation. In J. C. McCroskey, J. A. Daly, M. M. Martin, \& M. J. Beatty (Eds.), Communication and personality: Trait perspectives (pp. 133-148). Cresskill, NJ: Hampton Press.

Rush, S., Acton, L., Tolley, K., Marks-Maran, D., \& Burke, L. (2010). Using simulation in a vocational programme: does the method support the theory?. Journal of vocational education and training, 62(4), 467-479.

Wells, M. J., Wilkie, D. J., Brown, M. A., Corless, I. B., Farber, S. J., Judge, M. K. M., \& Shannon, S. E. (2002). Technology available in nursing programs: Implications for developing virtual end-of-life educational tools. Journal of Cancer Education, 17(2), 92-96. 